\title{
Trabulsiella guamensis
}

National Cancer Institute

\section{Source}

National Cancer Institute. Trabulsiella guamensis. NCI Thesaurus. Code C86823.

A species of aerobic, Gram negative, rod shaped bacteria assigned to the phylum

Proteobacteria. This species is oxidase negative, motile, fermentative, and

nonpigmented. T guamensis has a biochemistry profile similar to that of Salmonella sp.

and has been found in human stool but its pathogenicity is unknown. 